\title{
AlOx/AlGaAs technology for multi-plane integrated photonic devices
}

\author{
S. Calvez ${ }^{1,2}$, G. Lafleur ${ }^{1,2}$, A. Larrue ${ }^{1,2}$, P.-F. Calmon ${ }^{1,2}$, A. Arnoult ${ }^{1,2}$, \\ O. Gauthier-Lafaye ${ }^{1,2}$, G. Almuneau ${ }^{1,2}$ \\ ${ }^{1}$ CNRS, LAAS, 7 avenue du colonel Roche, F-31400 Toulouse, France \\ 2Univ de Toulouse, LAAS, F-31400 Toulouse, France \\ Tel: +33 5.61.33.69.90,Fax: +33 5.61.33.62.08,e-mail: scalvez@laas.fr
}

\begin{abstract}
The III-V semiconductor /oxide technology has become the standard fabrication technique for Vertical-Cavity Surface-Emitting Lasers. Current research aims to further enhance the performance of these emitters and diversify the range of devices that can be made using this technology.

In this paper, we present a new model of the oxidation process which includes the anisotropic behaviour observed during conventional lateral oxidation. Furthermore, we demonstrate that this technology can be used as an innovative method to make micro-disk resonators with vertically-coupled access waveguides, an approach which can be generalised to fabricate other types of multi-plane photonic devices.
\end{abstract}

Keywords: III-V semiconductor oxidation, anisotropy, microdisk resonators.

\section{INTRODUCTION}

The oxidation of III-V semiconductors is a process which selectively transforms high-aluminium-containing semiconductor alloys of high index of refraction $\left(\mathrm{n}_{\mathrm{AlAs}} \sim 2.9\right)$ into aluminium oxide (AlOx), an insulator with lower index of refraction $\left(\mathrm{n}_{\mathrm{AlOx}} \sim 1.6\right)$. Initially considered as a degradation and failure mechanism [1], this process has since then gained recognition and wide commercial success for its use in the fabrication of VerticalCavity Surface-Emitting Lasers where laterally-oxidized buried layers set the electrical injection profile and define the emission spatial mode content [2]. Recently, the research in this field has been primarily concerned with further expanding the capabilities of these oxide-confined VCSELs by improving their performance, for instance by increasing their modulation bandwidth thanks to multi-oxide layers [3], or by extending their wavelength coverage to the mid-infrared region [4]. However, a secondary strand of research activities on III-V semiconductor/AlOx technology has also emerged with the objective to further exploit the oxidation process [5] in wider range of devices including nonlinear optical converters [6][7], transistor lasers [8] or photovoltaic cells [9].

In this article, we present our recent contributions to the latter research strand. In particular, we report the characterisation and the analysis of the anisotropy of the oxide formation in AlGaAs. We also show how this technology can be exploited to create multiple-plane photonic devices and, more specifically, microdisk resonators that vertically-coupled to their access waveguides.

\section{ALGAAS WET OXIDATION: AN ANISOTROPIC PROCESS}

To-date, the oxidation of Al-containing III-V semiconductors (and AlGaAs in particular) has mostly been considered as an isotropic process. As a result, the oxidation of a thin (typically <100nm thick) layer is commonly treated as a one-dimensional phenomenon during which the lateral position of the oxide/semiconductor interface evolves as a function of the oxidation time. In essence, the established models are all based on the empirical law established by Deal and Grove [10] for the planar oxidation of silicon. Refinements have been added to take into account the effect of the finite thickness of the layer to be oxidized [11][12] and, to an extent, to include the first-order modification of the process dynamics resulting from the continuously varying perimeter of the oxide/semiconductor interface as the oxidation progresses [11][12][13].

A few reports have however highlighted that the process is actually anisotropic [14][15][16] although evidence of this fact could also be found in earlier work [17][2]. In particular, P.O. Vaccaro et al observed that oxidized thin AlGaAs layers on (110) and (311)-oriented GaAs substrates present an in-plane three-fold-symmetry anisotropy [14][15]. We have also shown that the oxidation of ( 500nm)-thick layers of AlGaAs on conventional (100)-GaAs substrates leads to tapered vertical profiles [16] whose tapered angle is attributed to the embedded strain resulting from the AlOx ( 7\%-)reduced volume compared to the AlGaAs material. 
Here, we draw the attention to the in-plane anisotropy observed upon oxidation of thin (68nm-thick) $\mathrm{Al}_{0.98} \mathrm{Ga}_{0.02} \mathrm{As}$ layers on (100)-oriented GaAs wafers and propose an extension of the model of the oxidation process to render this anisotropic behaviour.

To begin with, Figure 1 presents a sequence of infrared microscope images of the lateral oxidation of a $35 \mu \mathrm{m}-$ diameter disk from the edges a dry-etched circular mesa [18]. The sample was oxidised at $400^{\circ} \mathrm{C}$ in a reduced pressure environment ( 0.5 atm.), using a $\mathrm{H}_{2} / \mathrm{N}_{2} / \mathrm{H}_{2} \mathrm{O}$ gas steam mixture generated by an evaporator-mixer system operating at $95^{\circ} \mathrm{C}$. In the pictures, the [0 -11 1]-oriented sample cleaved edge is set along the horizontal axis and the oxide part appears in white while the remaining (central) AlAs section is light grey. This change in intensity is induced by the change in the multilayer stack reflectivity at the observation wavelength (790 nm) and is caused by the modification of the optical path in the $\mathrm{Al}_{0.98} \mathrm{Ga}_{0.02} \mathrm{As} / \mathrm{AlOx}$ layer upon oxidation. It can clearly be observed that the oxidation of the circular mesa tends towards a diamond-shaped aperture $\left(\mathrm{t}_{\mathrm{ox}}>100 \mathrm{~min}\right)$, highlighting that the process is indeed anisotropic with a faster reaction rate along the $\{0-10\}$ directions.

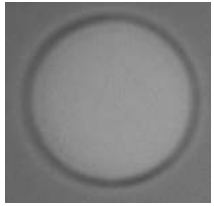

$\mathrm{t}=0 \mathrm{~min}$

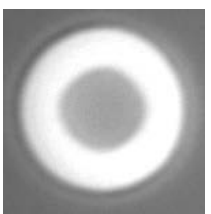

$\mathrm{t}=70 \mathrm{~min}$

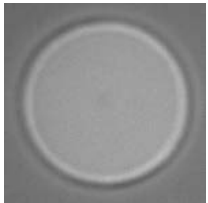

$\mathrm{t}=10 \mathrm{~min}$

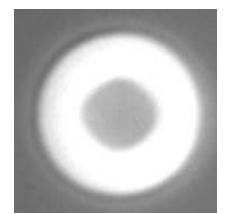

$\mathrm{t}=80 \mathrm{~min}$

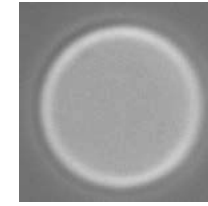

$\mathrm{t}=20 \mathrm{~min}$

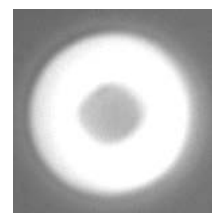

$\mathrm{t}=90 \mathrm{~min}$

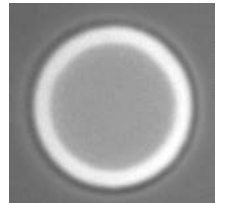

$\mathrm{t}=30 \mathrm{~min}$

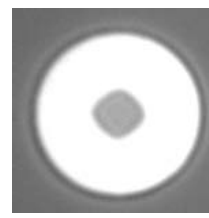

$\mathrm{t}=100 \min$

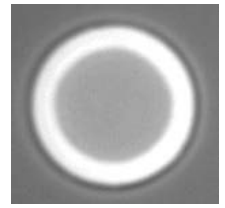

$\mathrm{t}=40 \mathrm{~min}$

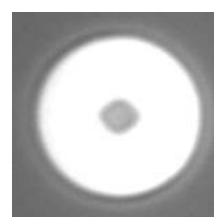

$\mathrm{t}=110 \mathrm{~min}$

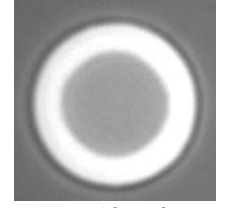

$\mathrm{t}=50 \mathrm{~min}$

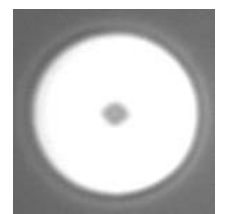

$\mathrm{t}=120 \mathrm{~min}$

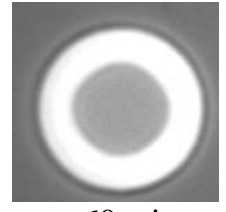

$\mathrm{t}=60 \mathrm{~min}$

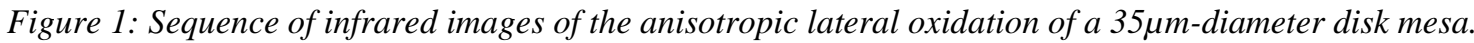

To more accurately reproduce this anisotropic oxidation, we simulate the oxidation using a truly bi-dimensional model where the oxidation process is considered to be the combination of an anisotropic reaction, which takes place at the oxide-semiconductor interface, and an isotropic diffusion process which accounts for the transfer of the reactants (and As-based by products) from the outer part of the mesa to the reaction interface (and viceversa).

Figure 2 shows the calculated oxidation contours (with a diffusion coefficient $\mathrm{D}=20 \mu \mathrm{m}^{2} / \mathrm{min}$, a fast reaction rate coefficient $\mathrm{k}_{\max }=0.12 \mu \mathrm{m} / \mathrm{min}$ and anisotropic factor $\mathrm{a}_{\text {aniso }}=0.1$ ) corresponding to the experimental oxidation process presented in Figure 1. The visual agreement between experimental data and numerical simulations confirms the appropriateness of the developed model.
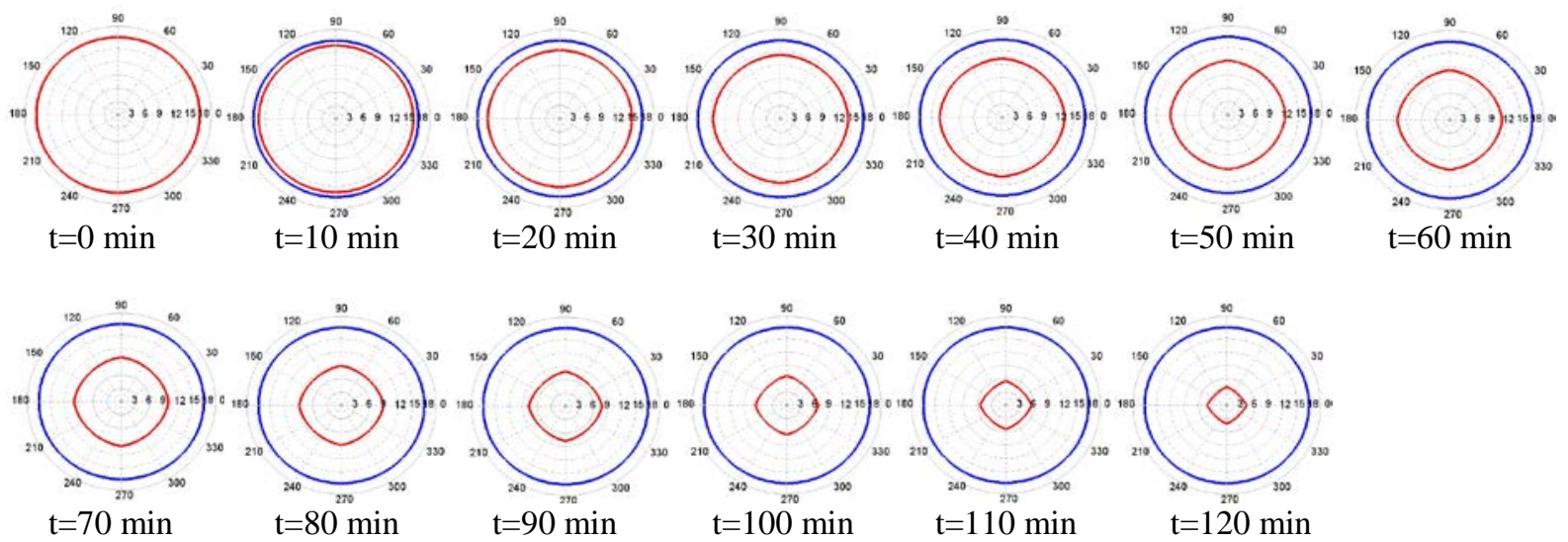

Figure 2: Sequence of calculated two-dimensional oxidation profiles (in red) of a 35 $\mu$ m-diameter disk (blue mesa) for regularly separated oxidation times ranging from 0 to 2 hours 


\section{VERTICALLY-COUPLED MICRODISK RESONATORS}

The ability to predict and in-situ monitor the oxidation of III-V compounds opens an avenue to realise photonic devices relying on oxidation patterns of greater complexity than VCSELs [1] or straight waveguides [5]. As an proof of principle, we have recently made microdisk resonators with vertically-coupled access waveguides [19]. The AlGaAs multi-layer stack is, in this case, constituted of two coupled GaAs waveguides whose coupling layer vertical structure includes two $\mathrm{Al}_{0.98} \mathrm{Ga}_{0.02} \mathrm{As}$ layers to be oxidized. The lower layer permits the introduction of the lateral confinement required to establish a buried rib-type access waveguide while the upper layer serves to significantly reduce the vertical coupling between the resonator and the remaining underlying slab waveguide. The transmission characteristics of a $75 \mu \mathrm{m}$-diameter microdisk (see Figure 2) revealed a $\mathrm{Q}$ factor of $\sim 4610$ for the fundamental whispering gallery modes of the microdisk, corresponding to an attenuation coefficient in the disk of $\sim 4.8 \mathrm{~cm}^{-1}$ and a coupling factor to the access waveguide of $64.8 \%$.

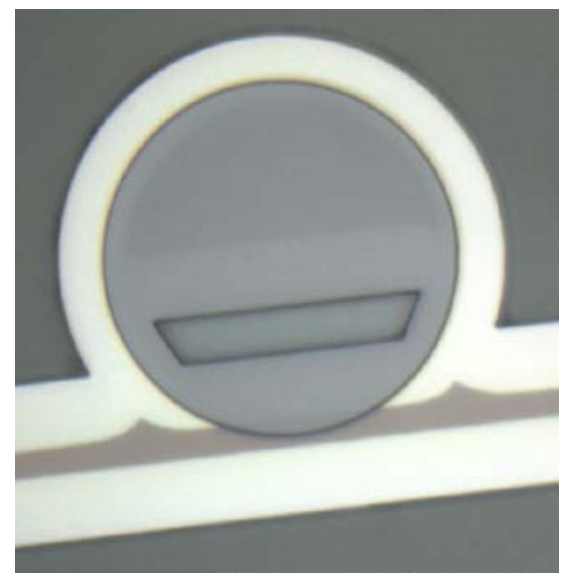

(a)

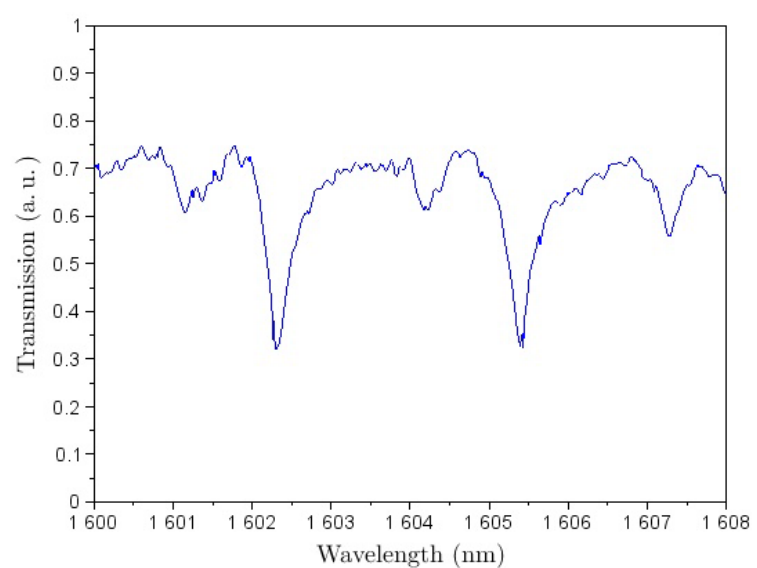

(b)

Figure 3: (a) Composite (IR, visible) image of a 75 $\mu$ m-diameter microdisk resonator coupled to its access waveguide. (b) Transmission characteristic of this device.

\section{CONCLUSIONS}

We have reported a new model of the oxidation of III-V semiconductor that takes into account the anisotropy of the process and demonstrated that this technology can be used to create multi-plane photonic devices via the fabrication of micro-disk resonators with vertically-coupled access waveguides.

\section{ACKNOWLEDGEMENTS}

The authors would like to acknowledge that this work was partly supported by the Centre National d'Etudes Spatial (CNES) and the French RENATECH network of micro-fabrication facilities. 


\section{REFERENCES}

[1] J. M. Dallesasse and D. G. Deppe, "III-V Oxidation: Discoveries and Applications in Vertical-Cavity Surface-Emitting Lasers,” Proc. IEEE, vol. 101, no. 10, pp. 2234-2242, Oct. 2013.

[2] K. D. Choquette, K. M. Geib, C. I. Ashby, R. D. Twesten, O. Blum, H. Q. Hou, D. M. Follstaedt, B. E. Hammons, D. Mathes, and R. Hull, “Advances in selective wet oxidation of AlGaAs alloys," Sel. Top. Quantum Electron. IEEE J. Of, vol. 3, no. 3, pp. 916-926, 1997.

[3] Y.-C. Chang and L. A. Coldren, "Efficient, High-Data-Rate, Tapered Oxide-Aperture Vertical-Cavity Surface-Emitting Lasers,” IEEE J. Sel. Top. Quantum Electron., vol. 15, no. 3, pp. 704-715, 2009.

[4] Y. Laaroussi, C. Chevallier, F. Genty, N. Fressengeas, L. Cerutti, T. Taliercio, O. Gauthier-Lafaye, P.-F. Calmon, B. Reig, J. Jacquet, and G. Almuneau, "Oxide confinement and high contrast grating mirrors for Mid-infrared VCSELs,” Opt. Mater. Express, vol. 3, no. 10, p. 1576, Oct. 2013.

[5] J. M. Dallesasse and N. Holonyak, “Oxidation of Al-bearing III-V materials: A review of key progress,” J. Appl. Phys., vol. 113, no. 5, p. 051101, 2013.

[6] A. Fiore, V. Berger, E. Rosencher, P. Bravetti, and J. Nagle, "Phase matching using an isotropic nonlinear optical material,” Nature, vol. 391, pp. 463-466, Jan. 1998.

[7] M. Savanier, C. Ozanam, L. Lanco, X. Lafosse, A. Andronico, I. Favero, S. Ducci, and G. Leo, "Nearinfrared optical parametric oscillator in a III-V semiconductor waveguide,” Appl. Phys. Lett., vol. 103, no. 26, p. 261105, Dec. 2013.

[8] G. Walter, N. Holonyak, M. Feng, and R. Chan, "Laser operation of a heterojunction bipolar light-emitting transistor,” Appl. Phys. Lett., vol. 85, no. 20, p. 4768, 2004.

[9] N. Pan, C. Youtsey, D. S. McCallum, V. C. Elarde, and J. M. Dallesasse, "High efficiency group iii-v compound semiconductor solar cell with oxidized window layer," US20100186822 A1, 20-Jul-2010.

[10] B. E. Deal and A. S. Grove, "General Relationship for the Thermal Oxidation of Silicon,” J. Appl. Phys., vol. 36, no. 12, p. 3770, 1965.

[11] M. Osinski, T. Svimonishvili, G. A. Smolyakov, V. A. Smagley, P. Mackowiak, and W. Nakwaski, "Temperature and thickness dependence of steam oxidation of AlAs in cylindrical mesa structures," Photonics Technol. Lett. IEEE, vol. 13, no. 7, pp. 687-689, 2001.

[12] Pei-Cheng Ku and C. J. Chang-Hasnain, "Thermal oxidation of AlGaAs: modeling and process control," IEEE J. Quantum Electron., vol. 39, no. 4, pp. 577-585, Apr. 2003.

[13] A. C. Alonzo, X.-C. Cheng, and T. C. McGill, "Effect of cylindrical geometry on the wet thermal oxidation of AlAs,” J. Appl. Phys., vol. 84, no. 12, p. 6901, 1998.

[14] P. O. Vaccaro, K. Koizumi, K. Fujita, and T. Ohachi, “AlAs oxidation process in GaAs/AlGaAs/AlAs heterostructures grown by molecular beam epitaxy on GaAs (n11) A substrates,” Microelectron. J., vol. 30, no. 4, pp. 387-391, 1999.

[15] K. Koizumi, P. O. Vaccaro, K. Fujita, M. Tateuchi, and T. Ohachi, "Lateral wet oxidation of AlAs layer in GaAs/AlAs heterostructures grown by MBE on GaAs (n11) A substrates,” J. Cryst. Growth, vol. 198, pp. 1136-1140, 1999.

[16] F. Chouchane, G. Almuneau, N. Cherkashin, A. Arnoult, G. Lacoste, and C. Fontaine, "Local stressinduced effects on AlGaAs/AlOx oxidation front shape,” Appl. Phys. Lett., vol. 105, no. 4, p. 041909, Jul. 2014.

[17] D. L. Huffaker, D. G. Deppe, K. Kumar, and T. J. Rogers, "Native-oxide defined ring contact for low threshold vertical-cavity lasers,” Appl. Phys. Lett., vol. 65, no. 1, p. 97, 1994.

[18] G. Almuneau, R. Bossuyt, P. Collière, L. Bouscayrol, M. Condé, I. Suarez, V. Bardinal, and C. Fontaine, "Real-time in situ monitoring of wet thermal oxidation for precise confinement in VCSELs," Semicond. Sci. Technol., vol. 23, no. 10, p. 105021, Oct. 2008.

[19] S. Calvez, G. Lafleur, A. Larrue, P.-F. Calmon, A. Arnoult, G. Almuneau, and O. Gauthier-Lafaye, "Vertically Coupled Microdisk Resonators Using AlGaAs/AlOx Technology," IEEE Photonics Technol. Lett., vol. 27, no. 9, pp. 982-985, May 2015. 